\title{
Qualidade dos Serviços Turísticos no Destino Pipa/Brasil: Um Estudo Sob a Ótica de Uma Análise de Cluster
}

\author{
Service Quality in Tourist Destination Pipa/Brazil: \\ A Study Based on a Cluster Analysis
}

\section{Calidad de los Servicios Turísticos en el Destino Pipa/Brasil: Un Estudio Bajo el Análisis de Cluster}

\section{Domingos Fernandes Campos ${ }^{1}$ Dalila Nathalia Bezerra Maia²}

\begin{abstract}
Resumo: O presente estudo tem como objetivo avaliar fatores de atratividade e a qualidade dos serviços no destino turístico Pipa/RN. Com base em 28 atributos, foram apreendidas as expectativas de 760 turistas. O serviço foi avaliado pelo modelo das lacunas, verificando a (des)confirmação entre expectativas e serviço percebido. Duas questões balizaram a avaliação: (a) em que medida as expectativas dos clientes variaram com os fatores sociodemográficos? (b) os agrupamentos obtidos pela análise de clusters foram orientados pelos fatores sociodemográficos? Os grupos apresentaram diferenças de prioridades em relação aos atributos e se diferenciaram pelo grau de exigência em relação ao serviço esperado.
\end{abstract}

Palavras-chave: Qualidade de serviço. Destino turístico. Análise de cluster.

Abstract: This study aims to evaluate the Attractiveness and Quality factors at the tourism services provided by Pipa/RN destination. Based on 28 services attributes, the expectations of 760 tourists have been collected. The service has been evaluated by Gap Model, verifying the (dis)confirmation of expectations and perceived service. Two questions have been used to evaluate: (a) Have the expectations been varied with the social and demographic factors? (b) Have the clusters identified by cluster analysis been guided by social and demographic factors? The groups identified were marked by different priorities in relation to the attributes and by different levels of demanding on expected service.

Keywords: Service quality. Tourist destinations. Cluster analysis.

Resumen: El presente trabajo evalua los factores de atractividad y la calidad de los servicios en el destino turístico Pipa (Brasil). En base a 28 atributos del servicio se establecieron las expectativas y se evaluó el desempeño con 760 turistas. El servicio fue evaluado por el modelo de las brechas de calidad. Dos preguntas básicas guiaron la investigación: (a) en que grado las expectativas de los clientes varian con los factores sociodemográficos? (b) los agrupamientos obtenidos por el análisis de clusters fueron orientados por factores sociodemográficos? Los grupos mostraron diferentes prioridades en relación con los atributos y fueron diferenciados por el nivel de exigencia en lo que se refiere al servicio esperado.

Palavras clave: Calidad de los servicios. Destinos turísticos. Análisis de cluster.

1 Universidade Potiguar. E-mail: domingos_campos@uol.com.br

2 Instituto Federal de educação do Rio Grande do Norte IFRN. E-mail: dalila_nath@hotmail.com 


\section{INTRODUÇÃO}

Muitos países fomentam o turismo como um motor para a produção do seu desenvolvimento econômico e priorizam uma forte atenção para a geração de divisas com o turismo internacional. Como qualquer outra atividade econômica, o turismo envolve a interação de pessoas, bens, serviços e meio ambiente (Ajagunna, 2014). O setor de serviços tem um papel destacado na economia mundial e a satisfação do consumidor tem sido buscada pelas empresas que querem sobreviver num campo de acirrada concorrência. A satisfação do cliente é uma resposta ao produto ou serviço oferecido, para o qual ele julga o valor das características daquilo que recebeu. $\mathrm{O}$ setor do turismo, formado essencialmente por serviços, é um dos setores de maior crescimento da atualidade. Para Campos \& Marodin (2013), o serviço turístico abarca vários setores da economia como o transporte, a alimentação, o lazer, a recreação e a hospedagem.

No Brasil, o turismo é reconhecido como fator considerável para o desenvolvimento econômico e social. Suas dimensões e diversidades de território resultam em uma extensa oferta de destinos turísticos e, apesar das crises econômicas de 2009 e 2011, o setor vem adaptando-se e buscando novos mercados. O turismo doméstico, impulsionado pelo aumento da renda média da população, do consumo familiar e pela emergência de uma nova classe média no Brasil constituem uma oportunidade ímpar para o fortalecimento do setor (Brasil, 2011).

O Estado do Rio Grande do Norte (RN) recebe aproximadamente 2,5 milhões de turistas ao ano e o setor gera cerca de 120 mil empregos. Reconhecido por suas belezas naturais, o RN é um dos principais destinos turísticos do Brasil. O desenvolvimento da atividade que começou na sua capital, Natal, hoje está presente em diversos municípios, com destaque para Tibau do Sul. Segundo o governo estadual, esse cenário foi construído a partir de investimentos conjuntos do poder público e do setor privado, por meio da construção de estradas e melhorias nas cidades e da instalação de hotéis, pousadas e restaurantes nas localidades turísticas (Rio Grande do Norte, 2012).

As consequências da exploração turística não se vinculam apenas ao seu impacto sobre a economia de uma região, mas também no impacto sobre a sociedade e o meio ambiente. A atratividade dos destinos turísticos tem sido explorada por vários autores com diferentes perspectivas. Tang \& Rochananond (1990) estudaram a atratividade de um destino turístico com base na análise de seus atributos. Hu \& Ritchie (1993) basearam-se nos sentimentos de crença e opinião dos visitantes em relação ao destino. Beerli \& Martín (2004); Chi \& Qu (2008) analisaram a imagem de um destino sob a perspectiva da análise da diferença entre a expectativa e o nível de satisfação dos visitantes em diferentes atributos.

A qualidade dos serviços é um fator crítico na escolha de um destino turístico. As caracteristicas de intagibilidade, heterogeneidade, inseparabilidade e aspectos culturalmente sensíveis dos serviços turísticos colocam desafios interessantes para os pesquisadores que tentam definir o que é atrativo para os turistas (Bajs, 2011). É necessário compreender como as relações entre o produto turístico, as percepções de qualidade e valores são geradas pelos visitantes para 
que sejam propostas e elaboradas ações em prol do alto nível de satisfação, considerando que turistas satisfeitos tendem a voltar ao destino e propagar suas experiências positivas para os amigos e familiares (Pavlic, Perucic \& Portolan, 2011; Murphy, Pritchard \& Smith, 2000).

A Praia de Pipa, no município de Tibau do Sul, Rio Grande do Norte, Brasil, despontou como um destino reconhecido tanto no âmbito nacional quanto internacional, atraindo diversos investimentos e acolhendo pessoas de diversas nacionalidades (Vidal, 2010). O município disponibiliza mais de 5.000 leitos distribuídos entre hotéis, pousadas e albergues com capacidade para receber 5.174 hóspedes por dia, sendo 85\% destes localizados na Praia de Pipa (IBGE, 2011). Em seus quinze quilômetros, a Praia oferece aos turistas aproximadamente 150 opções, entre bares, restaurantes e lanchonetes, que contemplam a gastronomia de várias partes do mundo. Anualmente, a Praia recebe cerca de 500 mil turistas (Secretaria do Turismo de Tibau do Sul, 2012).

O turismo sol e mar faz parte do leque de opções turísticas vinculadas ao meio ambiente. 0 desenvolvimento do turismo ecológico faz parte das grandes preocupações globais seja pelo número de pessoas que buscam essa atividade de lazer, seja pela necessidade premente de se preservar no âmbito mundial os recursos naturais. A escolha dos locais de passeio e lazer e a importância que cada um atribui aos diversos fatores que compõem o servico turístico dependem em certa medida de valores pessoais, culturais e do perfil sócio-econômico de cada turista. Saber em que medida esses visitantes têm necessidades e percepções diferenciadas - e como essas percepções se agrupam em grupos homogêneos de expectativas -, é importante para que os gestores de organizações privadas e de instituições públicas possam administrar e priorizar ações que visem o aprimoramento da oferta do serviço turístico.

O presente artigo tem como objetivo identificar e avaliar a composição de grupos homogêneos de turistas a partir de suas expectativas em relação aos fatores de atratividade e da qualidade dos serviços no destino turístico Pipa/RN. Duas questões balizaram a avaliação: (a) em que medida as expectativas dos clientes variaram com os fatores sociodemográficos? (b) os agrupamentos obtidos estatisticamente pela análise de clusters foram orientados pelos fatores sociodemográficos? Para a coleta de dados, foi utilizada uma amostra com 760 visitantes. 0 modelo das lacunas de Parasuraman, Zeithaml \& Berry (1985) foi utilizado na avaliação da qualidade dos serviços turísticos. O modelo avalia a qualidade do serviço com base no construto da (des)confirmação. A qualidade é medida pela diferença entre o desempenho do serviço percebido e as expectativas dos usuários sobre o mesmo.

O conceito da qualidade percebida foi originalmente definida por Grönroos (1984), como o resultado de um processo de avaliação em que o consumidor compara suas expectativas com o serviço que percebeu efetivamente receber, ou seja, contrapõe o serviço percebido e o serviço esperado. A qualidade de um serviço teria duas dimensões: uma dimensão técnica ou de resultado e uma dimensão funcional ou relacionada a processo. Parasuraman, Zeithaml \& Berry (1985) observaram o caráter multidimensional do fenômeno, ampliaram a discussão sobre os determinantes e a natureza da qualidade dos serviços e apresentaram o modelo das lacunas de 
qualidade. Quando o hiato entre desempenho e expectativas é positivo, os usuários tendem a mostrar-se satisfeitos. Ao contrário, os usuários tenderiam a ficar insatisfeitos com o déficit observado.

\section{REFERENCIAL TEORICO}

\subsection{Destinos Turísticos}

A concepção de destino tem sido explorada por vários autores a partir de diferentes perspectivas. Para alguns, um destino possui elementos territoriais, aspectos pessoais e econômicos, os quais atraem e recebem turistas, transformando-se em um produto turístico. Existe ainda um grupo de autores que adotam uma concepção holística, a qual define um destino turístico por meio da análise da integração de um grande número de agentes, organizações, redes, pessoas e grupos (Toro, Muñoza \& Moreno, 2010). Para Um \& Crompton (1990), a imagem é uma construção holística derivada de atitudes em relação aos atributos percebidos do destino de turismo e deriva de quatro perspectivas diferentes: um processo cognitivo envolve a percepção de estímulos, associando com as necessidades, avaliação de alternativas e avaliação se as expectativas foram cumpridas; uma ação fundamentada determinada pela atitude e pela influência de grupos sociais; uma escolha que maximiza a utilidade da estadia; e, a última, a participação no lazer que ofereça uma excitação ideal. A familiaridade com um local também pode ser decisiva na escolha de um de destino e envolve fatores como: distância geográfica, experiência de visitação anterior e nível de conhecimento geral sobre um destino (Hsu, Tsai \& Wu, 2009; Hu \& Ritchie,1993).

Kozak (2002) classifica-os em primários - clima, cultura, ecologia e arquitetura - e secundários como hotéis, transportes e toda estrutura derivada. Murphy, Pritchard \& Smith (2000) apontam que a percepção da qualidade do destino deriva diretamente dos serviços que os turistas recebem durante suas estadias e que a mesma é afetada tanto pelo ambiente quanto pela infraestrutura de serviços do destino. Os turistas também fazem comparações entre os atributos, as atrações e a qualidade de serviço entre os diferentes destinos, e, assim, estipulam o valor de certo destino individualmente (Kozak \& Remmington, 1999).

A competitividade do destino é um conceito geral que engloba preços, assim como os movimentos da taxa de câmbio, produtividade de vários componentes da indústria turística e fatores qualitativos que refletem a atratividade de um destino (Dwyer, Forsyth \& Rao, 2000). É necessário compreender como as relações entre o produto turístico e as percepções de qualidade e valores gerados, por parte dos visitantes, influenciam no ambiente competitivo. A crescente competitividade entre destinos turísticos aumenta o papel das atividades de marketing que devem trabalhar em prol do aumento do nível de satisfação, visto que turistas satisfeitos tendem a voltar ao destino e, principalmente, fazem propaganda positiva "boca-a-boca" (Pavlic, Perucic \& Portolan, 2011; Murphy, Pritchard \& Smith, 2000). 
Estudos Empíricos sobre Qualidade dos Serviços Turísticos

Hu \& Ritchie (1993) analisaram dois tipos diferentes de experiências de férias: uma voltada para educação e outra para diversão. Os resultados demonstraram que a importância dos atributos dos destinos varia significativamente com o contexto da experiência procurada de férias. Certas dimensões de atratividade de um destino podem ser percebidas de uma forma diferente, dependendo do contexto em que a decisão for feita.

O estudo de Toro, Muñoza \& Moreno (2010) realizado na Espanha destacou um grupo de fatores com maior importância nos serviços oferecidos por um destino turístico: qualidade dos serviços do hotel, o clima, a beleza da paisagem e a simpatia dos funcionários com os clientes. Verificou que a superlotação costuma ser a maior adversidade. Barros (2008) dissertou sobre a satisfação da qualidade de serviços na fidelização dos destinos turísticos de Cabo Verde. A pesquisa concluiu que o preço, as condições naturais, as atrações e a recreação foram os fatores que mais influenciaram a imagem de Cabo verde. A água do mar limpa e cristalina, a hospitalidade da população, a aparência e a simpatia dos empregados foram as características destacadas pelos turistas. A imagem do destino, analisada isoladamente, influenciou positivamente a satisfação e fidelização; a qualidade do serviço prestado influenciou positivamente a satisfação e a fidelização quando analisadas isoladamente.

Cardoso (2011) dissertou sobre a avaliação da qualidade do destino Figueira da Foz em Portugal. A pesquisa apontou oferta de jogos (cassino), paisagens naturais, hospitalidade, gastronomia e praias não superlotadas como os fatores nos quais Figueira da Foz tem melhor desempenho. A avaliação da qualidade de determinados atributos influencia positivamente a qualidade total do destino; a satisfação dos turistas influencia positivamente a fidelização. Bajs (2010) realizou entrevistas de profundidade com 20 pessoas com características sociodemográficas diferentes. Para os respondentes os atributos mais relevantes que podem afetar a avaliação de turistas são classificados em: qualidade da infraestrutura de serviços (hotéis, restaurantes entretenimento, informações turísticas, transportes), hospitalidade dos residentes e experiencias emocionais relacionadas a se divertir, descansar e se sentir seguro. A análise dos entrevistados indicou que os problemas sociais e os atributos de reputação não são relevantes para a percepção de turistas, seguido por qualidade de compras. Ademais, o tamanho do destino, os preços de lembranças e presentes e o custo de transporte local foram considerados atributos com menor importância.

Pizam, Neumann \& Reichel (1978) estudaram a satisfação dos turistas de Cape Cod, Massachusetts (EUA). Os autores identificaram oito fatores de satisfação dos turistas na área turística estudada: oportunidades de ir à praia, custo, hospitalidade, facilidades para comer e beber, instalações dos alojamentos, ambiente e extensão de comercialização. O estudo de Kozak (2002) comparou a satisfação de turistas britânicos e alemães na Turquia. Uma análise fatorial agregou as variáveis em oito fatores: serviços de alojamento, serviços de transporte, higiene e 
limpeza, hospitalidade e atendimento ao cliente, instalações e atividades, nível de preços, comunicação e linguagem de destino e serviços aeroportuários.

No estudo de Hsu, Tsai \& Wu (2009), realizado em Taiwan, foram identificados fatores que influenciam a escolha do destino pelos turistas e avaliam suas preferências pelos mesmos. Os resultados indicaram que visitar amigos/parentes e segurança pessoal foram os fatores mais importantes para os turistas. Preço foi o menos importante. Wu, Zhang \& Fujiwara (2011) também analisaram o processo de escolha dos destinos turísticos. Os dados foram colhidos em 29 destinos turísticos do Japão. Utilizaram sete atributos, divididos em sócio-demográficos e relacionados à viagem. Os fatores que mais influenciaram as escolhas foram tempo de viagem, a atratividade do destino e número de pontos de turísticos. Gênero, idade e estado civil também apresentaram efeitos notáveis sobre a escolha do destino de viagem.

Dey \& Sarma (2010) estudaram o uso das fontes de informações no processo de escolha de destinos turísticos no nordeste da Índia. Para cumprir os objetivos do estudo, o questionário foi elaborado a partir de duas questões - uma relacionada à motivações da viagem e a outra em relação à fontes de informação. Os resultados apontaram que as informações através de amigos/parentes/colegas são as que mais influenciam os entrevistados. Fakeye \& Crompton (1992) analisaram as diferenças de motivações para revisitar ou visitar pela primeira vez o destino turístico de Lower Rio Grande Valley no Texas (EUA). Para os que se dirigiam pela primeira vez a esse destino, o desejo de fugir do clima frio do inverno do Meio Oeste e satisfazer a curiosidade de visita eram as principais motivações. Para os que revisitavam, a motivação principal foram as relações sociais com o círculo de amizades.

Beerli \& Martín (2004) fizeram uma análise quantitativa sobre as características dos turistas e da imagem percebida dos visitantes de Lanzarote na Espanha. O estudo identificou a influência das características dos turistas ou fatores pessoais sobre os diferentes componentes da imagem percebida no destino turístico. Os resultados indicaram que as motivações influenciam o componente afetivo da imagem: a experiência de viagem de férias tem uma relação significativa com imagens cognitivas e afetivas, e as características sócio-demográficas também influenciam a avaliação cognitiva e afetiva da imagem de um destino turístico. Chi e Qu (2008) examinaram as relações estruturais entre imagem, satisfação e fidelidade de um destino turístico no estado de Arkansas (EUA). Os resultados apoiaram a proposta de modelo de lealdade destino: a imagem de destino é diretamente influenciada pela satisfação de atributos; a imagem de um destino e a satisfação dos atributos são ambos antecedentes diretos da satisfação global, e a satisfação global e a satisfação do atributo por sua vez, tem impacto direto e positivo na lealdade destino.

Cracolici \& Nijkamp (2008), avaliaram a competitividade das regiões turísticas da Itália com base na análise das percepções dos turistas. Concluíram que informações, serviços turísticos, eventos culturais, qualidade e variedade de produtos nas lojas, hotéis, preços e segurança foram os fatores mais significativos. Os fatores da oferta turística (recepção e simpatia dos moradores locais, cidades artísticas e culturais, paisagem, ambiente e natureza), em termos de vantagem comparativa, tiveram um menor efeito sobre a avaliação de visitantes. Enright \& Newton (2004) 
estudaram em Hong Kong, os fatores associados à competitividade dos destinos turísticos. Os respondentes foram solicitados a classificar os atributos em relação à importância e à competitividade relativa da cidade. Segurança, gastronomia, vida noturna e apelo visual foram os atributos com maior importância e com maior contribuição à competitividade do destino. $\mathrm{Na}$ análise de Kozak \& Rimmington (1999), o destaque foi concedido à competitividade do destino turístico Turquia na percepção dos turistas britânicos. De acordo com a pesquisa, o conjunto de atributos que contribui para a competitividade da Turquia é: a hospitalidade, valor para o dinheiro, clima, segurança, transporte local e o ambiente natural.

Rodrigues (2010) dissertou sobre a análise comparativa da competitividade dos destinos turísticos de Algarve/Portugal em contraste com o sul da Espanha. Foi realizada uma pesquisa quantitativa por meio de uma análise dos dados disponíveis nos organismos oficiais dos países de Portugal e da Espanha. $O$ estudo foi baseado no modelo composto por sete variáveis divididas em 23 indicadores. As variáveis que mais contribuíram para a diferenciação de um destino foram: patrimônio cultural e infraestrutura. As variáveis menos diferenciadoras do desempenho competitivo de um destino foram: preço e competitividade social.

Tang \& Rochananon (1990) analisaram os fatores que tornavam um país mais atraente para os turistas, apoiado em atributos como: beleza natural e clima, características da cultura e social; esporte, recreação e educação; estabelecimentos comerciais; infraestrutura do país, custo de vida; atitudes para com os turistas e acessibilidade do país. Trinta e dois países foram selecionados para o estudo. Ao final, Estados Unidos, Tailândia, Suíça, Austrália, Áustria e foram classificados nos dez melhores pelos entrevistados. Países como a China, Índia, Egito, Hong Kong, Iugoslávia e Filipinas receberam as menores notas em termos de atratividade turística. Os resultados indicaram também que a beleza natural e características de clima, cultura e social, custo de vida e hospitalidade foram considerados fatores importantes de todos os grupos de entrevistados na escolha de um destino turístico. A acessibilidade do país e seus estabelecimentos comerciais foram considerados menos importante.

\section{METODOLOGIA}

A investigação iniciou-se com um levantamento preliminar acerca do contexto local e entrevistas realizadas com gestores e turistas voltados para a compreensão das especificidades do destino turístico. O esquema metodológico é apresentado na Figura 1. 
Figura 1 - Esquema metodológico da pesquisa

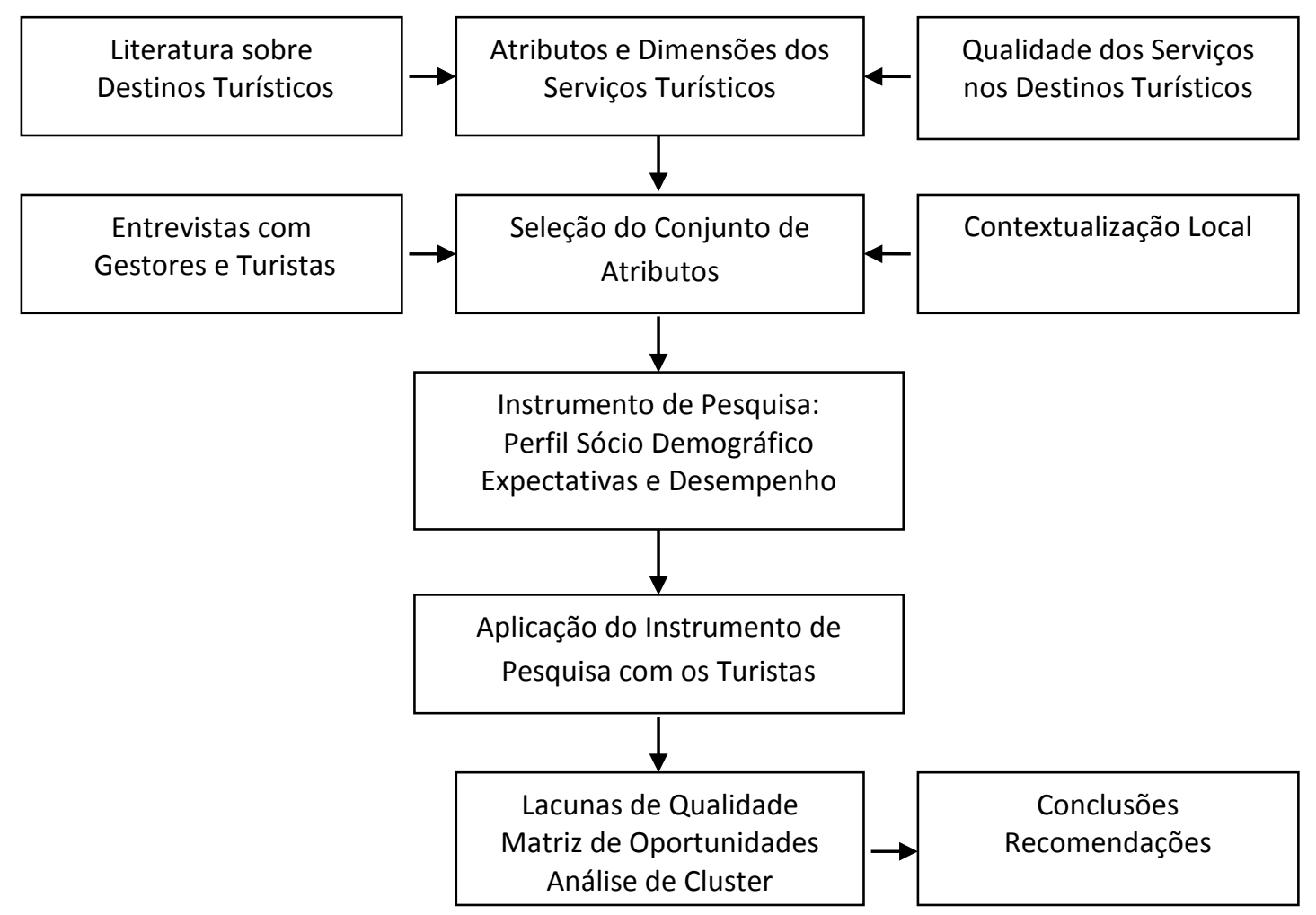

Fonte: Elaborado pelos autores

Com base nos estudos empíricos, foram levantados 664 atributos da qualidade do serviço nos destinos turísticos, os quais passaram por uma análise criteriosa com a finalidade de remover distorções, ambiguidades ou determinantes repetidos, permitindo uma maior precisão e clareza dos atributos. Para tanto, foram utilizados os critérios de completude, justaposição, similaridade, conteúdo continente, consistência, precisão, especificidade, clareza e representatividade para selecionar e refinar os atributos. Mediante esses critérios, foi possível pré-selecionar 51 atributos da qualidade do serviço nos destinos turísticos para serem utilizados na presente pesquisa.

Para a escolha definitiva dos atributos, foi necessária a adequação ao contexto local da pesquisa. Desse modo, foram realizadas entrevistas com elementos da indústria do turismo em Pipa/RN. Foram entrevistados: 10 prestadores de serviços, 10 gerentes de restaurantes, 10 gerentes de meios de hospedagem, 10 comerciantes e 10 turistas/veranistas. Nessa etapa foram coletados 21 atributos que foram confrontados com os 51 atributos oriundos da revisão da literatura. Ao final foram selecionados 28 atributos para compor o instrumento de pesquisa. A Figura 2 aponta os 28 atributos utilizados e suas respectivas definições. 
Figura 2 - Conjunto de atributos utilizados na pesquisa

\section{Descrição dos atributos}

1. Acessibilidade: sinalização nas estradas, disponibilidade de meios de transporte para chegar ao local, distância de aeroporto/rodoviária/porto.

2. Acesso às atrações turísticas: facilidade de deslocamento, meios de transportes, sinalização das atrações.

3. Segurança local: policiamento, sensação de segurança em andar pelas ruas, índice de criminalidade.

4. Disponibilidade de serviços e equipamentos de saúde: conjunto de estabelecimentos destinados a prestar serviços preventivos/assistência da área de saúde, postos de saúde, hospitais, ambulâncias, farmácias, clinicas.

5. Sistema de comunicação: conjunto de meios disponíveis para serem utilizados pela população residente e pelos visitantes, como sinal de telefonia móvel e fixa, acesso à internet, correios.

6. Disponibilidade de hotéis, restaurantes e entretenimento.

7. Agradabilidade do clima: condições meteorológicas - temperatura, pressão, ventos, umidade e chuvas.

8. Tranquilidade e calma no local: Disponibilidade de ambientes voltados para o descanso.

9. Fama do destino: Reputação, propaganda, status do destino.

10. Combate à prostituição e ao turismo sexual: ações que combatam a prostituição e o turismo sexual

11.Variedade e beleza das atrações naturais: diversidade de atrações naturais - falésias, praias, lagoas, reservas naturais, sítios ecológicos, fauna.

12. Limpeza e manutenção dos espaços públicos: limpeza e manutenção de ruas, praças, praias.

13. Preservação das atrações naturais: falésias, praias, lagoas, reservas naturais, sítios ecológicos, fauna.

14. Disponibilidade de equipamentos/ serviços nas praias: disponibilidade de banheiros públicos, rampas, escadas, aluguel de cadeiras nas praias do destino.

15. Diversidade cultural dos frequentadores: possibilidades de interação com pessoas de diferentes culturas e países.

16. Diversidade na oferta de passeios turísticos e atividades de lazer.

17. Disponibilidade de festivais sazonais: oferta de eventos gastronômicos, musicais, literários.

18. Disponibilidade de variedade de restaurantes e bares: diversidade nas especialidades: italiano, regional, frutos do mar, vegetariano, entre outros.

19. Variedade na oferta de meios de hospedagem: variedade de estabelecimentos destinados a prestação de serviços de hospedagem: hotéis, pousadas, albergues, camping. resorts, hotéis.

20. Agradabilidade dos meios de hospedagem: arquitetura, decoração, instalações, limpeza, conforto.

21. Agradabilidade dos estabelecimentos comerciais: arquitetura, decoração, instalações, limpeza conforto.

22. Hospitalidade dos residentes: acolhimento, cordialidade, presteza dos moradores do local.

23. Relação qualidade/preço dos meios de hospedagem: custo-benefício do valor pago.

24. Relação qualidade/preço nos restaurantes e bares: custo-benefício do valor pago em comida e bebida.

25. Variedade na oferta de estabelecimentos comerciais e de serviços: variedade de segmentos de lojas no destino turístico - vestuário, acessórios, artesanato, salão de beleza, farmácia, etc.

26. Horário de funcionamento do comércio: horário de funcionamento do comércio local.

27. Disponibilidade de espaços públicos para passeios, caminhadas e pontos de encontro: disponibilidade de ruas para pedestres, praças, orlas, parques para a população e visitantes.

28. Disponibilidade de informações sobre o destino turístico para a o planejamento da viagem.

Fonte: Pesquisa 


\subsection{Instrumento de Pesquisa}

Para a fase quantitativa da pesquisa foi desenvolvido um questionário com três módulos. $\mathrm{O}$ primeiro contemplou questões voltadas aos aspectos sócio-demográficos. O segundo foi composto para apreender as expectativas dos turistas sobre os atributos do serviço apontados no Quadro 1. Os respondentes apontaram suas expectativas mediante o grau de importância e importância conferido a cada atributo sobre uma escala Likert de 11 pontos, variando de zero (não importante) a dez (muito importante). O terceiro módulo contemplou os mesmos atributos do anterior; aqui, os respondentes avaliaram o desempenho dos serviços do destino Pipa/RN, sobre uma escala similar variando de zero (péssimo) a dez (excelente). Uma questão adicional avaliou o serviço turístico como um todo. $O$ instrumento de pesquisa passou por um processo de validação, através de pré-testes com cinco especialistas, cinco empresários de Pipa/RN, vinte estudantes universitário de turismo e vinte turistas de $\mathrm{Pipa} / \mathrm{RN}$, possibilitando os últimos ajustes no questionário definitivo.

\subsection{Universo, Amostra e Coleta de Dados}

O universo do presente estudo caracteriza-se pelos turistas de Pipa/RN nos meses de março e abril de 2013, com pelo menos um dia de hospedagem no destino. Por desconhecer-se o número exato de visitantes, a população foi tratada como infinita. A amostra foi estratificada por gênero e por faixa etária, a partir das médias dos resultados das pesquisas de demanda turísticas de Pipa/RN realizadas pela Secretaria de Turismo/RN nos anos de 2008 e 2009. O cálculo amostral foi desenvolvido admitindo-se um erro de 3,5\%, p=0,5 e nível de confiança de $95 \%$, o que resultou no tamanho da amostra de 784 respondentes. A aplicação dos questionários foi realizada por uma equipe de seis universitários devidamente treinados. Os turistas foram abordados em hotéis, bares, restaurantes e pontos de encontro.

\section{RESULTADOS}

Os resultados apresentados refletem a apuração das respostas atribuídas em 760 questionários válidos dos turistas de Pipa/RN. Como a amostra prevista era de 784 respondentes, o erro foi recalculado para 3,55\%. A composição de gênero e faixas etárias obedeceu aos critérios de estratificação da amostra. Majoritariamente, destaca-se no perfil sócio-demográfico um grupo de alta escolaridade, que viaja a lazer com a família e que já visitou Pipa/RN pelo menos uma vez antes. Os visitantes são oriundos principalmente das regiões Nordeste $(61,3 \%)$ e Sudeste $(19,7 \%)$. A Tabela 1 apresenta o perfil sócio-demográfico completo da amostra. 
Tabela 1 - Perfil sócio-demográfico da amostra

\begin{tabular}{|c|c|c|c|}
\hline Gênero & & Rend & \\
\hline Feminino & $55,3 \%$ & Menos de 2 SM & $6,3 \%$ \\
\hline Masculino & $44,7 \%$ & 2 a 5 SM & $35,7 \%$ \\
\hline Idade & & 6 a 10 SM & $30,5 \%$ \\
\hline Até 17 anos & $1,3 \%$ & 11 a 20 SM & $18,3 \%$ \\
\hline 18 a 25 anos & $15,8 \%$ & $+20 \mathrm{SM}$ & $9,2 \%$ \\
\hline 26 a 35 anos & $37,8 \%$ & Viajou ao des & \\
\hline 36 a 50 anos & $32,5 \%$ & Família & $67,9 \%$ \\
\hline 51 a 65 anos & $11,2 \%$ & Amigos & $25,9 \%$ \\
\hline+65 anos & $1,4 \%$ & Sozinho & $3,9 \%$ \\
\hline Escola & & Outros & $2,2 \%$ \\
\hline Básico & $2,3 \%$ & Motivo d & \\
\hline Médio & $18,9 \%$ & Lazer & $96,7 \%$ \\
\hline Universitário & $17,0 \%$ & Trabalho & $3,0 \%$ \\
\hline Graduado & $43,6 \%$ & Congresso/Evento & $0,0 \%$ \\
\hline PósGraduado & $18,3 \%$ & Outros & $0,3 \%$ \\
\hline Ocupação principal & & Hos & \\
\hline Funcionário público & $24,2 \%$ & Hotel Resort Flat & $40,8 \%$ \\
\hline Funcionário privado & $32,6 \%$ & Pousada Albergue & $37,9 \%$ \\
\hline Aposentado & $4,3 \%$ & Casa de amigos & $11,1 \%$ \\
\hline Empresário & $14,5 \%$ & Casa de veraneio & $5,5 \%$ \\
\hline Estudante & $11,8 \%$ & Outros & $4,7 \%$ \\
\hline Outro & $12,5 \%$ & & \\
\hline Tempo de permanência & & Número & \\
\hline 1 a 3 noites & $62,6 \%$ & Uma vez & $47,4 \%$ \\
\hline 4 a 7 noites & $27,1 \%$ & Duas vezes & $15,8 \%$ \\
\hline 8 a 14 noites & $5,0 \%$ & Três vezes & $8,7 \%$ \\
\hline + 14 noites & $5,3 \%$ & +4 vezes & $28,2 \%$ \\
\hline
\end{tabular}

Fonte: Pesquisa

\subsection{Importância e Lacunas da Qualidade do Serviço em Pipa/RN}

Com base na média das respostas sobre expectativas (grau de importância) e desempenho sobre o conjunto de 28 atributos, foram calculadas as lacunas de qualidade do serviço no destino turístico Pipa. 0 grau de importância dos atributos para os turistas variou de um mínimo de 7,43 (fama do destino) até o máximo de 9,46 (preservação das atrações naturais). As lacunas de qualidade - calculadas como a diferença entre as médias de desempenho e importância - variaram entre os extremos de -2,62 (combate à prostituição e ao turismo sexual) e 1,81 (fama do destino turístico). Quanto mais negativo for a lacuna, maior o déficit de qualidade do serviço naquele atributo.

Assim, na percepção dos turistas, Pipa carece de uma ação mais efetiva dos gestores no combate à prostituição e ao turismo sexual. Por outro lado, os turistas perceberam na fama do destino um superávit de 1,81 . Isso quer dizer que os turistas avaliaram Pipa positivamente no que se refere à fama. Veja que a qualidade não é atribuída pela média de desempenho e sim pela diferença entre o desempenho e a expectativa. A Tabela 2 apresenta os resultados apurados. Os atributos estão listados em ordem de importância. A coluna RI representa a ordem dos atributos pela importância; o valor 1 aponta o atributo com maior importância. A coluna RL, a ordem dos atributos pela magnitude das lacunas; o valor 1 aponta o atributo com maior déficit de qualidade. 
Tabela 2 - Importância e lacunas da qualidade do serviço em Pipa/RN

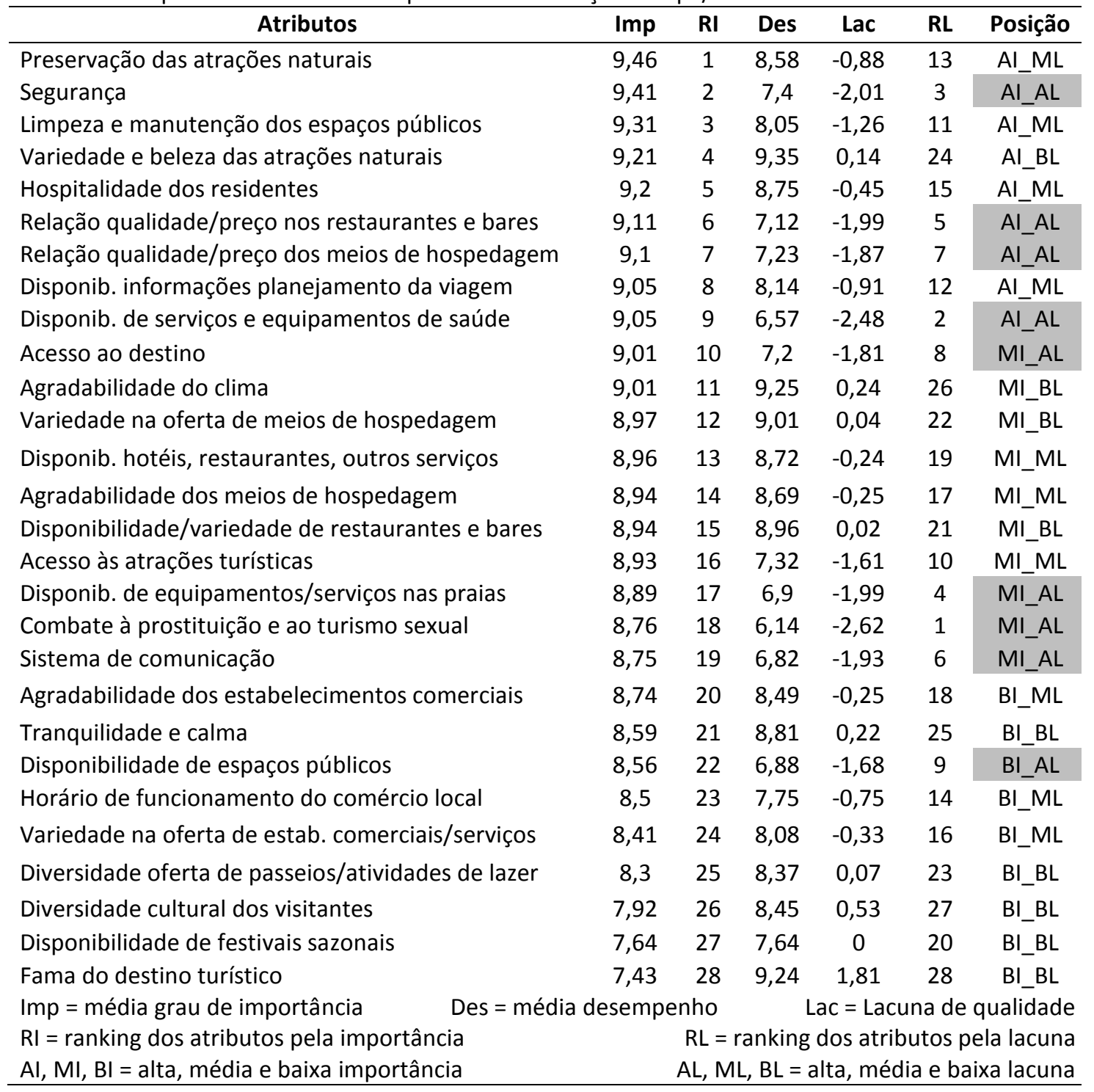

Fonte: Pesquisa

Na Tabela 2, coluna <Posição>, estão marcados atributos que obtiveram maiores déficts de qualidade (maiores lacunas). Os atributos que obtiveram simultaneamente as maiores lacunas de qualidade e os maiores graus de importância - marcados com Al_AL -, são aqueles que devem merecer uma atenção prioritária dos gestores. Assim, segurança, relação qualidade/preço nos meios de hospedagens e nos restaurantes e bares, e disponibilidade de serviços e equipamentos de saúde clamam por uma ação mais decisiva dos gestores públicos e privados. A contraposição importância $x$ desempenho, aqui empreendida, é similar a matriz de oportunidades sugerida por Stock \& Lambert (2001). 


\subsection{Identificação de Grupos Homogêneos de Turistas}

De acordo com Hair et al. (2005, p. 33), a análise de agrupamentos ou análise de clusters "é uma técnica que classifica uma amostra de entidades (indivíduos ou objetos) em um pequeno número de grupos mutuamente excludentes, com base na similaridade entre as entidades". Essa técnica estatística foi utilizada para identificar os grupos de turistas que visitaram o destino Pipa/RN, sendo estes formados em conformidade com as notas de importância conferidas a cada um dos 28 atributos pesquisados. Foi empregado o método hierárquico Ward, por apresentar solução simples e conglomerados com tamanhos mais homogêneos. A análise escolhida foi a que distribui os respondentes em três clusters. A Tabela 3 apresenta o perfil com base nos dados sócio-demográficos.

Tabela 3 - Perfil dos componentes dos clusters

\begin{tabular}{|c|c|c|c|c|c|c|c|}
\hline & Cluster 1 & Cluster 2 & Cluster 3 & & Cluster & Cluster 2 & Cluster 3 \\
\hline $\begin{array}{l}\text { Tamanho } \\
\text { Gênero }\end{array}$ & 172 & 421 & 167 & $\begin{array}{c}\text { Tamanho } \\
\text { Renda }\end{array}$ & 172 & 421 & 167 \\
\hline Feminino & $54,7 \%$ & $52,5 \%$ & $62,9 \%$ & Menos de 2 & $6,4 \%$ & $6,2 \%$ & $6,6 \%$ \\
\hline $\begin{array}{l}\text { Masculino } \\
\text { Idade }\end{array}$ & $45,3 \%$ & $47,5 \%$ & $37,1 \%$ & $\begin{array}{l}2 \text { a } 5 \text { SM } \\
6 \text { a } 10 S M\end{array}$ & $\begin{array}{l}33,1 \% \\
30,8 \%\end{array}$ & $\begin{array}{l}40,1 \% \\
30,4 \%\end{array}$ & $\begin{array}{l}26,9 \% \\
30,5 \%\end{array}$ \\
\hline Até 17 anos & $0,6 \%$ & $1,7 \%$ & $1,2 \%$ & 11 a 20 SM & $20,3 \%$ & $15,7 \%$ & $22,8 \%$ \\
\hline $18-25$ anos & $13,4 \%$ & $15,7 \%$ & $18,6 \%$ & $+20 \mathrm{SM}$ & $9,3 \%$ & $7,6 \%$ & $13,2 \%$ \\
\hline 26-35 anos & $39,0 \%$ & $36,6 \%$ & $39,5 \%$ & Viajou com & & & \\
\hline $36-50$ anos & $36,0 \%$ & $31,8 \%$ & $30,5 \%$ & Família & $72,7 \%$ & $68,9 \%$ & $60,5 \%$ \\
\hline $51-65$ anos & $9,3 \%$ & $12,6 \%$ & $9,6 \%$ & Amigos & $22,1 \%$ & $24,5 \%$ & $33,5 \%$ \\
\hline+65 anos & $1,7 \%$ & $1,7 \%$ & $0,6 \%$ & Sozinho & $3,5 \%$ & $3,8 \%$ & $4,8 \%$ \\
\hline Escola & & & & Outros & $1,7 \%$ & $2,9 \%$ & $1,2 \%$ \\
\hline Básico & $2,9 \%$ & $2,6 \%$ & $0,6 \%$ & Motivo & & & \\
\hline Médio & $20,3 \%$ & $20,0 \%$ & $15,0 \%$ & Lazer & $94,8 \%$ & $98,1 \%$ & $95,2 \%$ \\
\hline Universitário & $17,4 \%$ & $15,2 \%$ & $21,0 \%$ & Trabalho & $5,2 \%$ & $1,9 \%$ & $3,6 \%$ \\
\hline Graduado & $34,9 \%$ & $48,0 \%$ & $41,3 \%$ & Eventos & $0,0 \%$ & $0,0 \%$ & $0,0 \%$ \\
\hline Pós Grad & $24,4 \%$ & $14,3 \%$ & $22,2 \%$ & Outros & $0,0 \%$ & $0,0 \%$ & $1,2 \%$ \\
\hline Ocupação & & & & Hospeda & & & \\
\hline Func Pub & $21,5 \%$ & $25,2 \%$ & $24,6 \%$ & Hotel e Flat & $38,4 \%$ & $43,7 \%$ & $35,9 \%$ \\
\hline Func Priv & $34,3 \%$ & $32,1 \%$ & $32,3 \%$ & Pousada & $44,8 \%$ & $46,6 \%$ & $47,3 \%$ \\
\hline Aposentado & $3,5 \%$ & $5,5 \%$ & $2,4 \%$ & Casa amigos & $4,7 \%$ & $1,7 \%$ & $3,0 \%$ \\
\hline Empresário & $18,0 \%$ & $14,3 \%$ & $11,4 \%$ & Casa verão & $7,0 \%$ & $3,8 \%$ & $8,4 \%$ \\
\hline Estudante & $8,1 \%$ & $11,2 \%$ & $17,4 \%$ & Outros & $5,2 \%$ & $4,2 \%$ & $5,4 \%$ \\
\hline Outro & $14,5 \%$ & $11,9 \%$ & $12,0 \%$ & & & & \\
\hline Tempo & & & & Visitas & & & \\
\hline 1 a 3 noites & $63,4 \%$ & $62,5 \%$ & $62,3 \%$ & Uma vez & $46,5 \%$ & $53,2 \%$ & $33,5 \%$ \\
\hline 4 a 7 noites & $21,5 \%$ & $28,7 \%$ & $28,7 \%$ & Duas vezes & $10,5 \%$ & $14,0 \%$ & $25,7 \%$ \\
\hline 8 a 14 noites & $8,7 \%$ & $3,6 \%$ & $4,8 \%$ & Três vezes & $8,1 \%$ & $8,3 \%$ & $10,2 \%$ \\
\hline+14 noites & $6,4 \%$ & $5,2 \%$ & $4,2 \%$ & + Quatro & $34,9 \%$ & $24,5 \%$ & $30,5 \%$ \\
\hline
\end{tabular}

Fonte: Pesquisa

Comparando os perfis sócio-demográficos dos três grupos, é possível perceber diferenças mais acentuadas no Cluster 3. Nele, percebe-se maior presença das mulheres, mais escolaridade, mais jovens, menos empresários e mais estudantes, renda familiar mais elevada, viajam com amigos e já visitaram Pipa com maior frequência. Sugere um perfil dos visitantes "mais relax" e "descolado". 


\subsection{As Expectativas por Grupos Homogêneos}

A Tabela 4 mostra as médias das expectativas dos turistas classificados por grupo (cluster). Para cada atributo são mostrados a média geral das expectativas, a média das expectativas por cluster e seus respectivos rankings. As últimas duas colunas da tabela mostram qual dos clusters obteve a maior (Max) e a menor (Min) expectativa. Nitidamente, observa-se que o Cluster 2 obteve as maiores médias das expectativas - 26 dentre os 28 atributos; O Cluster 3, por outro lado, obteve as menores médias das expectativas -23 dos 28 atributos.

Tabela 4 - Médias e rankings de importância dos atributos por cluster

\begin{tabular}{|c|c|c|c|c|c|c|c|c|c|c|}
\hline \multirow{2}{*}{ Atributos } & \multicolumn{2}{|c|}{ Geral } & \multicolumn{2}{|c|}{ Cluster 1} & \multicolumn{2}{|c|}{ Cluster 2} & \multicolumn{2}{|c|}{ Cluster 3} & \multicolumn{2}{|c|}{ Média } \\
\hline & Med & $\mathbf{R}$ & Med & $\mathbf{R}$ & Med & $\mathbf{R}$ & Med & $\mathbf{R}$ & Max & $\mathbf{M i}$ \\
\hline Preservação das atrações naturais & 9,46 & 1 & 9,79 & 1 & 9,77 & 1 & 8,34 & 4 & $\mathrm{C} 1$ & $\mathrm{C} 3$ \\
\hline Segurança & 9,41 & 2 & 9,48 & 3 & 9,77 & 2 & 8,43 & 1 & $\mathrm{C} 2$ & C3 \\
\hline Limp e manutenção espaços públicos & 9,31 & 3 & 9,70 & 2 & 9,67 & 3 & 8,00 & 11 & $\mathrm{C} 1$ & C3 \\
\hline Variedade e beleza das atrações naturais & 9,21 & 4 & 9,05 & 6 & 9,63 & 5 & 8,31 & 5 & $\mathrm{C} 2$ & $\mathrm{C} 3$ \\
\hline Hospitalidade dos residentes & 9,20 & 5 & 9,10 & 4 & 9,55 & 9 & 8,43 & 2 & $\mathrm{C} 2$ & C3 \\
\hline Relação qualidade/preço rest e bares & 9,11 & 6 & 8,49 & 17 & 9,65 & 4 & 8,37 & 3 & $\mathrm{C} 2$ & $\mathrm{C} 3$ \\
\hline Relação qualid./preço hospedagem & 9,10 & 7 & 8,66 & 14 & 9,61 & 6 & 8,27 & 6 & $\mathrm{C} 2$ & C3 \\
\hline Disp. de informações para a viagem & 9,05 & 8 & 8,99 & 7 & 9,39 & 19 & 8,26 & 7 & $\mathrm{C} 2$ & C3 \\
\hline Disp. serviços e equip de saúde & 9,05 & 9 & 9,10 & 5 & 9,56 & 8 & 7,72 & 18 & $\mathrm{C} 2$ & C3 \\
\hline Acesso ao destino & 9,01 & 10 & 8,82 & 11 & 9,59 & 7 & 7,74 & 17 & $\mathrm{C} 2$ & C3 \\
\hline Agradabilidade do clima & 9,01 & 11 & 8,97 & 8 & 9,40 & 17 & 8,07 & 9 & $\mathrm{C} 2$ & C3 \\
\hline Variedade na oferta de hospedagem & 8,97 & 12 & 8,80 & 12 & 9,50 & 10 & 7,79 & 14 & $\mathrm{C} 2$ & C3 \\
\hline Disp. de hotéis, restaurantes e entreten. & 8,96 & 13 & 8,92 & 9 & 9,40 & 16 & 7,88 & 13 & $\mathrm{C} 2$ & C3 \\
\hline Disp. variedade de rest e bares & 8,94 & 14 & 8,62 & 15 & 9,48 & 13 & 7,92 & 12 & $\mathrm{C} 2$ & $\mathrm{C} 3$ \\
\hline Agradabilidade meios de hospedagem & 8,94 & 15 & 8,61 & 16 & 9,42 & 15 & 8,06 & 10 & $\mathrm{C} 2$ & C3 \\
\hline Acesso às atrações turísticas & 8,93 & 16 & 8,78 & 13 & 9,50 & 11 & 7,66 & 20 & $\mathrm{C} 2$ & $\mathrm{C} 3$ \\
\hline Disp.e de equipamentos/serviços praias & 8,89 & 17 & 8,89 & 10 & 9,39 & 18 & 7,63 & 22 & $\mathrm{C} 2$ & $\mathrm{C} 3$ \\
\hline Combate à prostituição turismo sexual & 8,76 & 18 & 8,04 & 21 & 9,49 & 12 & 7,66 & 19 & $\mathrm{C} 2$ & C3 \\
\hline Sistema de comunicação & 8,75 & 19 & 8,40 & 18 & 9,42 & 14 & 7,43 & 24 & $\mathrm{C} 2$ & C3 \\
\hline Agradabilidade estabelecimentos & 8,74 & 20 & 8,11 & 20 & 9,37 & 20 & 7,79 & 15 & $\mathrm{C} 2$ & $\mathrm{C} 3$ \\
\hline Tranquilidade e calma & 8,59 & 21 & 8,34 & 19 & 9,07 & 23 & 7,65 & 21 & $\mathrm{C2}$ & $\mathrm{C} 3$ \\
\hline Disp.espaços públicos para passeios & 8,56 & 22 & 7,72 & 23 & 9,23 & 22 & 7,76 & 16 & $\mathrm{C} 2$ & $\mathrm{C} 1$ \\
\hline Horário de funcionamento do comércio & 8,50 & 23 & 7,54 & 24 & 9,06 & 24 & 8,07 & 8 & $\mathrm{C} 2$ & $\mathrm{C} 1$ \\
\hline Variedade estab. comerciais e serviços & 8,41 & 24 & 7,20 & 26 & 9,24 & 21 & 7,58 & 23 & $\mathrm{C} 2$ & $\mathrm{C} 1$ \\
\hline Divers.e na oferta de passeios e lazer & 8,30 & 25 & 7,81 & 22 & 8,91 & 25 & 7,26 & 25 & $\mathrm{C} 2$ & C3 \\
\hline Divers. cultural dos visitantes & 7,92 & 26 & 7,38 & 25 & 8,42 & 26 & 7,23 & 26 & $\mathrm{C} 2$ & C3 \\
\hline Disponibilidade de festivais sazonais & 7,64 & 27 & 6,47 & 27 & 8,29 & 27 & 7,21 & 27 & $\mathrm{C} 2$ & $\mathrm{C} 1$ \\
\hline Fama do destino turístico & 7,43 & 28 & 6,40 & 28 & 8,06 & 28 & 6,89 & 28 & $\mathrm{C} 2$ & $\mathrm{C} 1$ \\
\hline
\end{tabular}

Med = média das expectativas no cluster Max = cluster com a maior média no atributo

Fonte: Pesquisa

É possível constatar, ademais, a diferença nas amplitudes de expectativas quando observados os clusters individualmente. As médias para o Cluster 1 variaram de um mínimo de 6,40 (fama do destino turístico) a uma máximo de 9,79 (preservação das atrações naturais), uma 
amplitude de 3,39 pontos na escala. Para o Cluster 2, a amplitude foi de 1,71 pontos, variando de 9,77 (preservação das atrações naturais) a 8,06 (fama do destino turístico). O Cluster 3 teve a menor amplitude com 1,54 pontos, variando de 8,43 (segurança) a 6,89 (fama do destino turístico).

$\mathrm{Na}$ análise cluster realizada, os grupos foram discriminados pelo padrão das expectativas dos visitantes. Quanto maior a expectativa maior o grau de importância para o visitante. Os resultados apontam que o Cluster 2 é constituído por visitantes mais exigentes, com expectativas acima dos outros dois grupos. O Cluster 3 é constituído por um grupo de turistas menos exigentes, apontando expectativas bem mais baixas que os outros dois grupos na grande maioria dos atributos. Os níveis de expectativas do Cluster 1 revelam valores intermediários entre os outros dois grupos. A Figura 3 mostra os níveis de expectativas por cluster em cada um dos 28 atributos.

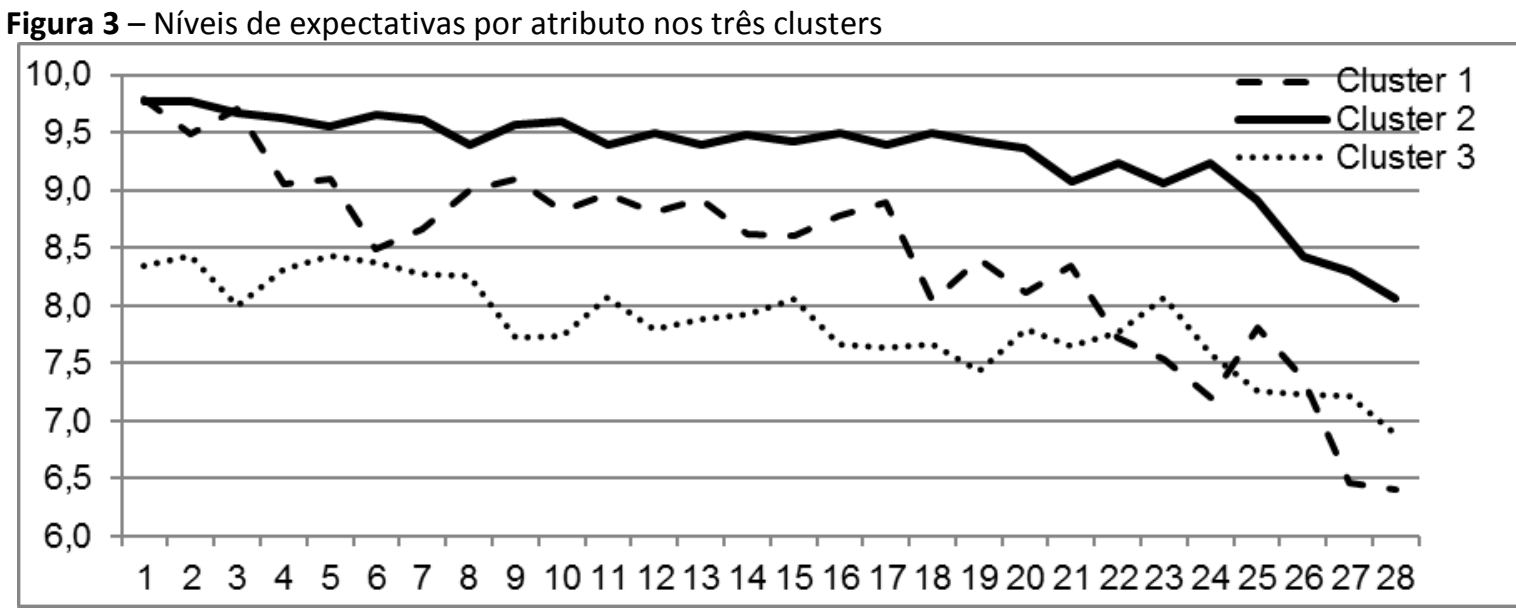

Fonte: Pesquisa

O padrão de expectativas de um grupo de clientes pode ser avaliado pelo nível das exigências e pelas ordem de prioridades firmada entre atributos. Os grupos escolhidos têm níveis de exigências (expectativas) diferenciados. Analisando-se as hierarquias dos clusters (ranking) mostradas na Tabela 4, verifica-se que há divergências na ordem dos atributos, embora ocorram algumas coincidências. Todos os grupos apontaram disponibilidade de festivais sazonais e fama do lugar nas duas últimas posições. Observando os atributos postos no primeiro terço da Tabela 4 (mais importantes), verifica-se que em nenhum deles há um alinhamento das posições, embora alguns ocupem posições muito próximas. Uma medida do (des)alinhamento dos rankings pode ser estabelecida pelo teste de correlação de Spearman. Um completo alinhamento daria um coeficiente 1. A Tabela 5 mostra os resultados do teste. 
Tabela 5 - Coeficientes de correlação entre os ranks dos clusters

\begin{tabular}{lcll}
\hline & \multicolumn{2}{c}{ Teste de Correlação de Spearman } & \\
& Cluster 1 & Cluster 2 & Cluster 3 \\
\hline Cluster 1 & 1,000 & $0,784^{* *}$ & $0,667^{* *}$ \\
Cluster 2 & - & 1,000 & $0,686^{* *}$ \\
Cluster 3 & - & - & 1,000 \\
$* *$ Significativo para alfa $=1 \%$ (bi-caudal) & & \\
\hline Fonte: Pesquisa & &
\end{tabular}

Assim, além dos grupos se diferenciarem pelo nível das expectativas, também se diferenciam pela na prioridade que concedem aos mesmos atributos. O Cluster 2 é constituído por pessoas mais exigentes, com expectativas acima dos outros dois grupos. O Cluster 3 é constituído por um grupo de turistas menos exigentes, apontando expectativas bem mais baixas que os outros dois grupos na grande maioria dos atributos.

\subsection{A Qualidade Percebida por Grupos Homogêneos}

A qualidade percebida está vinculada à diferença entre desempenho e expectativas em cada atributo (lacunas). O perfil de desempenho de cada grupo é mostrado na Figura 4. Observase claramente que o Cluster 3 foi mais rigoroso na avaliação geral (atribuiu notas mais baixas) e o Cluster 2 foi o menos rigoroso, atribuindo notas mais altas. Na pesquisa, os visitantes foram demandados a responder uma questão sobre o desempenho de Pipa como um todo, independentemente do atributo. A média observada para os Cluster 3 foi 8,44; para o Cluster 2, média de 8,98. O Cluster 1 apontou 8,62, confirmando, no geral, a mesma sequencia da avaliação na maioria dos atributos.

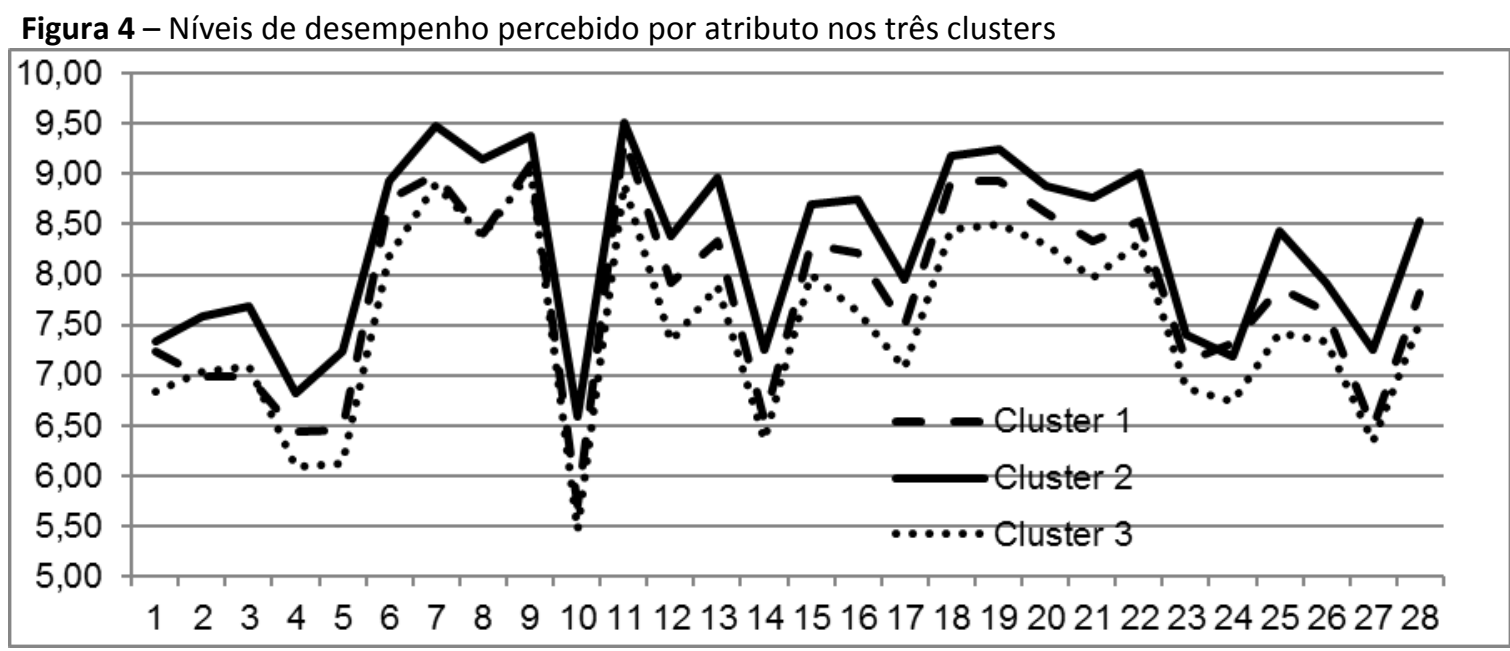

Fonte: Pesquisa

Quando observadas as lacunas da qualidade percebida, constata-se que mesmo com a avaliação de desempenho tomada mais rigorosamente, o Cluster 3 percebe, na maioria dos atributos, déficits menores de qualidade (quando negativas) e superavits maiores de qualidade 
quando positivas. Em dezenove dos vinte e oito atributos, o Cluster 3 avaliou a qualidade dos serviços no destino Pipa/RN em um nível melhor que os outros dois grupos. A Figura 5 mostra as lacunas de qualidade.

Figura 5 - Lacunas da qualidade percebida por atributo nos três clusters

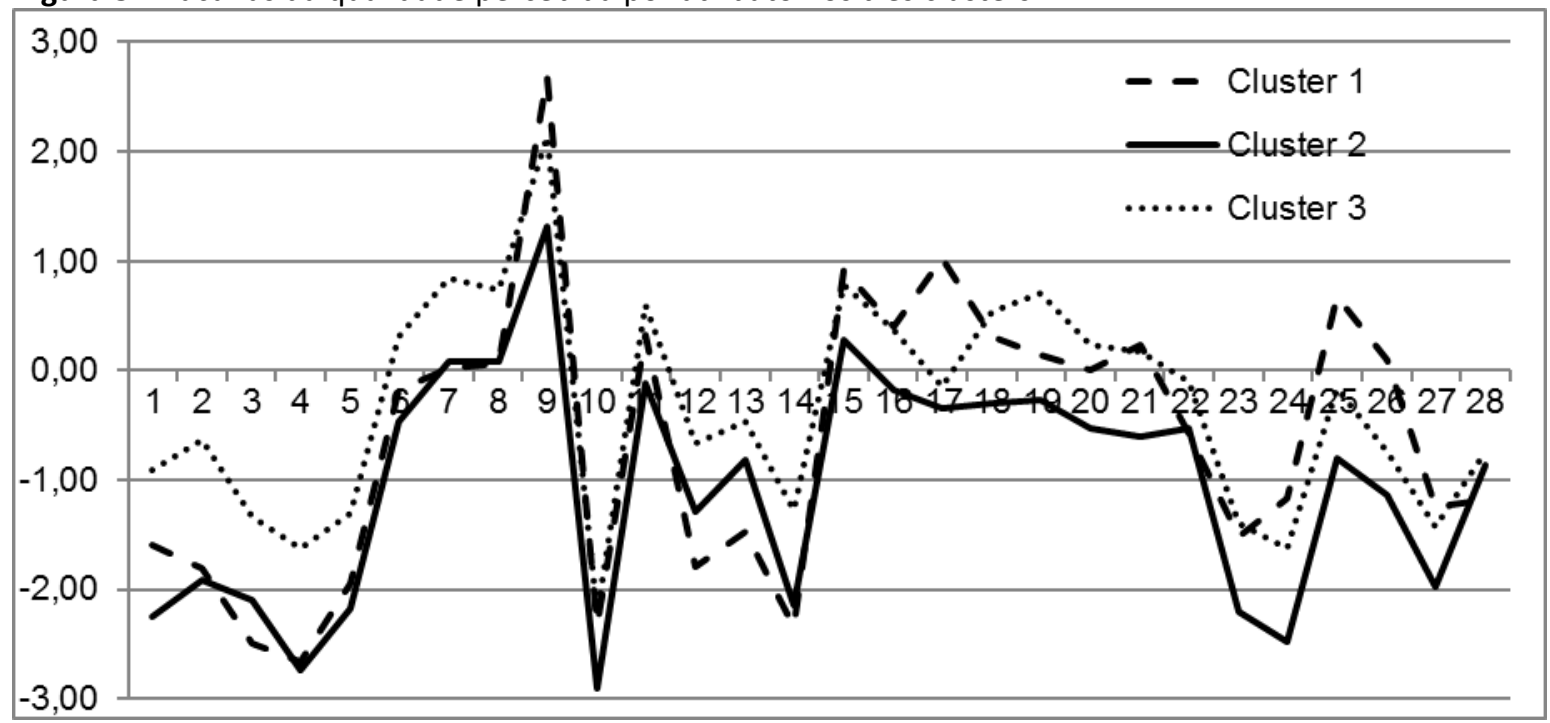

Fonte: Pesquisa

\section{CONCLUSÃO}

Em relação à importância referida a cada atributo, os resultados indicaram que foi apontado um maior nível de importância para o atributo preservação das atrações naturais e o menor nível de importância para o atributo fama dos destinos turísticos. Igualmente tiveram um alto nível de importância os atributos: segurança, limpeza e manutenção dos espaços públicos, variedade e beleza das atrações naturais, hospitalidade dos residentes, relação qualidade/preço nos restaurantes e bares, relação qualidade/preço dos meios de hospedagem, disponibilidade de informações para a preparação da viagem e disponibilidade de serviços e equipamentos de saúde.

Ao examinar as lacunas de qualidade, verificou-se uma predominância de lacunas negativas, indicando que grande parte dos serviços oferecidos no destino Pipa/RN está abaixo da expectativa geral dos turistas. Dos 28 atributos utilizados na pesquisa, 19 apresentaram lacunas negativas e 09 lacunas apresentaram valores iguais ou maiores que zero. Combate à prostituição e ao turismo sexual teve a lacuna de qualidade mais negativa e fama do destino turístico teve a maior lacuna positiva.

Com a contraposição das expectativas (grau de importância) com a magnitude das lacunas, foi possível construir a matriz absoluta de oportunidades do destino Pipa/RN. Os resultados enfatizaram a necessidade melhorar definitivamente os atributos: segurança, relação qualidade/preço dos restaurantes e bares, relação qualidade/preço dos meios de hospedagem e disponibilidade de serviços e equipamentos de saúde. Ademais, figuram como muito importantes para os turistas - e que deveriam receber a atenção dos gestores para melhorar o desempenho 
porque têm lacunas de média magnitude - os serviços relacionados à preservação das atrações naturais, limpeza e manutenção dos espaços públicos, hospitalidade dos residentes e disponibilidade de informações para o planejamento da viagem. Dentre os atributos mais importantes figurou, ainda, a variedade e beleza das atrações naturais do lugar. Nesse quesito, no entanto, Pipa recebeu a avaliação mais positiva dos turistas, repercutindo com uma lacuna muito pequena em relação às necessidades.

Quanto à identificação de grupos homogêneos de turistas, constatou-se que a diferenciação entre grupos notabilizou-se por significativas diferenças em relação ao padrão de expectativas. Os três grupos que emergiram da análise de conglomerados apresentaram diferenças de prioridades em relação aos atributos e se diferenciaram pelo grau de exigência em relação aos níveis de serviço esperados. O Cluster 3 apresenta um perfil sócio-demográfico próximo ao que a linguagem cotidiana chama de "mais relax" e "descolado". Podem priorizar o que os demais grupos apreciam, mas, por estarem mais habituados ao lugar, mantêm, uma expectativa mais baixa em relação àquilo que podem receber.

A matriz de oportunidades e a análise dos clusters oferecem importantes subsídios para a ação dos gestores, seja na esfera privada, seja na esfera pública. Em ambos os casos, é possível planejar e construir uma base de oferta dos serviços mais próxima e mais sintonizada com as necessidades dos clientes, ainda que estas apresentem diferenciais importantes quando tomadas em diferentes grupos.

\section{REFERÊNCIAS}

Ajagunna, Ibrahim (2014) "New world, new tourism, new destinations: implications for emerging economies and lessons for old tourism-dependent developing economies". Worldwide Hospitality and Tourism Themes 6 (2): 103-117.

Bajs, I. P. (2010) "Attributs of tourism destination as determinants of tourist perceived value". International Journal of Manangement Cases 8: 547-554.

Barros, J. L. G. (2008) "A satisfação com a qualidade de serviços na fidelização dos destinos turísticos". Dissertação de Mestrado. Faculdade de Economia da Universidade do Porto, Porto.

Beerli, A. \& Martin, J. D. (2004) "Tourists' characteristics and the perceived image of tourist destinations: a quantitative analysis-a case study of Lanzarote, Spain". Tourism Management 25(1): 623-636.

Brasil. (2011) Roteiros do Brasil. Disponível em: http://www.turismo.gov.br/export/ sites/default/turismo/o ministerio/publicacoes/downloads publicacoes/Revista_Roteiros do Brasil _ internet.pdf.

Acesso em: 01 ago 2012.

Campos, D. F. \& Marodin, T. G. (2013) "El uso de matrices de oportunidad para el análisis de los servicios hoteleros en la ciudad de Natal, Brasil". Estudios y Perspectivas en Turismo 22(4): 661-681.

Cardoso, J. M. O. (2011) "Avaliação da qualidade de destinos turísticos: destino Figueira da Foz". Dissertação de Mestrado. Departamento de Economia, Gestão e Engenharia Industrial. Universidade de Aveiro, Aveiro. 
Chi, C. G. \& Qu, H. (2008) "Examining the structural relationships of destination image, tourist satisfaction and destination loyalty: an integrated approach". Tourism Management 29(4): 624-636.

Cracolici, M. F. \& Nijkamp, P. (2008) "The attractiveness and competitiveness of tourist destinations: a study of southern italian regions". Tourism Management 30(3): 336-344.

Dey, B. \& Sarma, M. K. (2010) "Information source usage among motive-based segments of travelers to newly emerging tourist destinations". Tourism Management 31(3): 341-344.

Dwyer, L.; Forsyth, P. \& Rao, Pr. (2000) "The price competitiveness of travel and tourism: a comparison of 19 destinations". Tourism Management 21(1): 9-22.

Enright, M. J. \& Newton, J. (2004) "Tourism destination competitiveness: a quantitative approach". Tourism Management 25(6): 777-788.

Fakeye, P. C. \& Crompton, J. L. (1992) "Importance of Socialization to Repeat Visitation". Journal Annals of Tourism Research_19 (2): 364-367.

Grönroos, C. (1984) A service quality model and its marketing implications". European Journal of Marketing 18(4): 36-44.

Hair J. F.; Anderson, R. E.; Tatham, R. L. \& Black, W. C. (2005) Análise multivariada de dados. Bookman, Porto Alegre.

Hsu, T.; Tsai, Y. \& Wu, H. (2009) "The preference analysis for tourist choice of destination: A case study of Taiwan". Tourism Management 30(2): 288-297.

Hu, Y. \& Ritchie, J. B. (1993) "Measuring destination attractiveness: a contextual approach". Journal of Travel Research 32(2): 25-34.

IBGE (2011) "Pesquisa de Serviços de hospedagem". Diretoria de Pesquisas, Coordenação de Serviços e Comércio, Rio de Janeiro.

Kozak, M. \& Rimmington, M. (1999) "Measuring tourist destination competitiveness: conceptual considerations and empirical findings". Hospitality Management 18(3): 273-283.

Kozak, M. (2002) "Comparative analysis of tourist motivations by nationality and destinations". Tourism Management 23(3): 221-232.

Murphy, P.; Pritchard, M. P. \& Smith, B. (2000) "The destination product and its impact on traveller perceptions". Tourism Management 21(1): 43-52.

Parasuraman, A.; Zeithaml, V. \& Berry, L. L. (1985) "A conceptual model of service quality and its implications for future research". Journal of Marketing 49(4): 41-50.

Pavlic, I.; Perucic, D. \& Portolan, A. (2011) "Tourists' satisfaction as an important tool for increasing tourism destination competitiveness in the globalization conditions - the case of Dubrovnik-Neretva County". International Journal of Management Cases 9: 591-599. 
Pizam, A.; Neumann, Y \& Reichel, A. (1978) "Dimentions of tourist satisfaction with a destination area". Annual of Tourism Research 5(3): 314-322.

Rio Grande do Norte. (2012) Conheça o turismo. Disponível em: www.rn.gov.br/conheca-o-rn/turismo/. Acesso em: 01 jun 2012.

Rodrigues, L. M. (2010) "A análise comparativa da competitividade dos destinos turísticos: o caso de Algarve versus o Sul de Espanha". Dissertação de Mestrado. Faculdade Economia. Universidade do Algarve, Faro.

Secretaria do Turismo de Tibau do Sul (2012) "Dados do turismo". Tibau do Sul.

Stock, J. \& Lambert, D. (2001) “Strategic Logistics Management”. McGraw-Hill, New York .

Tang, J. C. S \& Rochananond, N. (1990) "Attractiveness as a tourist destination: a comparative study of Thailand and selected Countries". Socio-Economic Planning Sciences 24(3): 229-236.

Toro, A. L.; Muñoza, R. \& Moreno S. (2010) "An assessment of the quality of a tourist destination: the case Nerja, Spain". Total Quality Management, 21 (3): 369-289.

Um, S. \& Crompton, J. L. (1990) "Attitude determinants in tourism destination choice". Annals of Tourism Research, 17(3): 432-448.

Vidal, Soraia M. S. C. (2010) "Dunas, lagoas e praias - turismo e sustentabilidade em Natal, RN". Revista Ponto-e-Vírgula, 7, p. 77-94, 2010.

Wu, L.; Zhang, J. \& Fujiwara, A. (2011) "Representing tourists' heterogeneous choices of destination and travel party with an integrated latent class and nested logit model". Tourism Management 32(6): 14071413.

Artigo recebido em: 20/03/2015. Artigo aprovado em: 19/08/2015. 